\title{
Mpl receptor defect leads to earlier appearance of hematopoietic cells/hematopoietic stem cells in the Aorta- Gonad-Mesonephros region, with increased apoptosis
}

\author{
MAUD FLEURY1,2, LAURENCE PETIT-COCAULT1,2,\#, DENIS CLAY2,3 and MICHĖLE SOUYRI*,1,2,\# \\ 1'Inserm U602, ${ }^{2}$ Université Paris-Sud, Institut André Lwoff and ${ }^{3}$ Institut André Lwoff (IFR89), Villejuif, France
}

\begin{abstract}
In a previous study, we underlined the functional role of the TPO receptor, Mpl, in the establishment of definitive mouse hematopoiesis, by demonstrating that the lack of Mpl led to a delayed production of definitive hematopoietic cells in the aorta-gonad-mesonephros (AGM) region, and resulted in the production of hematopoietic stem cells (HSCs) with an impaired activity at E11.5. In order to more accurately estimate the role of Mpl during generation of HSCs in the aorta, we performed an analysis of these AGMs at the time of the first HSC emergence (E10.5). Our results indicated that while Mpl-/- AGMs were found to contain more hematopoietic cells (HC) than C57BI6 AGMs at E10.5, a defect in the expansion process of the HC/HSCs was detected in explant cultures of these AGMs, likely due to an increased apoptosis of these cells. To determine the molecular mechanisms by which invalidation of Mpl receptor affects the temporal distribution and expansion of HC/HSCs in the AGM, a study of the transcription level of of Mpl target genes was conducted. Expression of Runx1, a master transcription factor for the formation of hematopoietic progenitor (HP) cells and HSCs from the vasculature, as well as expression of Meis1 and HoxB4, known to play a role in self-renewal and expansion of HSCs, were found to be down regulated in $\mathrm{E} 10.5 \mathrm{Mpl} / /$ - AGMs. Our data indicate that $\mathrm{Mpl}$ is an active player during the first steps of definitive hematopoiesis establishment through direct regulation of the expression of transcription factors or genes important for the self-renewal, proliferation and apoptosis of HSCs.
\end{abstract}

KEY WORDS: Mpl receptor, HSC, AGM, apoptosis, Runx1

\section{Introduction}

In the mouse the first definitive intraembryonic Hematopoietic Stem Cells (HSCs) are generated in the aorta, in the AortaGonad-Mesonephros (AGM) region, at embryonic day 10.5 (E10.5) (de Bruijn etal., 2000; Godin etal., 1993; Medvinsky and Dzierzak, 1996; Medvinsky et al., 1993). The microenvironment provided by the AGM site plays a key role in this process, and extensive analysis of this microenvironment can reveal important regulatory molecules which direct blood cell development. One of the key molecules involved in cluster formation is the transcription factor Runx1. Runx1 is the DNA-binding subunit of the heterodimeric transcription factor Runx1-CBF $\beta$ and it is a specific marker of hematopoietic clusters in many species (North et al., 1999; Bollerot et al., 2005). Embryos deficient for Runx1 show no hematopoietic clusters, and do not display any detectable HSC (North et al., 1999; Cai et al., 2000; Yokomizo et al., 2001; North et al., 2002). Very recently, Runx 1 function has been demonstrated to be essential in endothelial cells for the formation of hematopoietic progenitors (HP) and HSCs from the vasculature (Chen et al., 2009). It is reasonable to hypothesize that cytokines and their receptors, which are important in promoting HSC selfrenewal, proliferation and differentiation in the adult, could also represent critical regulators in the establishment of definitive hematopoiesis. Indeed, a recent body of data support this assumption, since IL-3 was found to be an important embryonic HSC regulator as a proliferation and survival factor for the earliest HSCs in the embryo (Robin et al., 2006), and IL-1 was shown to

\footnotetext{
Abbreviations used in this paper: AGM, Aorta-Gonad-Mesonephros region; FACS, fluorescence activated cell sorting; HC, hematopoietic cell; HSC, hematopoietic stem cell; Mpl, myeloproliferative leukemia; TPO, thrombopoietin.
}

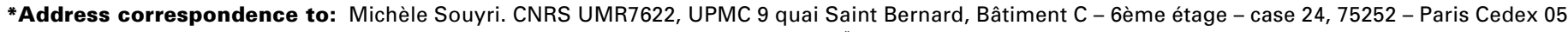
Tel: +33-1-4427-5961. Fax: +33-1-4427-3497. e-mail: michele.souyri@snv.jussieu.fr \#Present address: UPMC - CNRS UMR7622, Paris, France
} 
play a role in the normal regulation of $\mathrm{HP} / \mathrm{HSC}$ in the midgestation mouse AGM (Orelio et al., 2008). Our own work underlined the functional role of the TPO receptor, Mpl, in the establishment of definitive mouse hematopoiesis: we demonstrated that the lack of $\mathrm{Mpl}$ led to a delayed production of definitive hematopoietic cells in the AGM region, and resulted in the production of HSCs with an impaired activity in E11.5 AGM (Petit-Cocault et al., 2007).

In the present study, we tried to more accurately estimate the role of Mpl during the generation of HSCs in the aorta as well as the molecular mechanisms which are deficient in E10.5 Mpl-/AGM. By comparing the hematopoietic content of E10.5 Mpl-/- and C57BI6 AGMs, we could show that indeed Mpl-/- AGMs contain more hematopoietic cells (HC) than C57BI6 AGMs. However, explants cultures allowed to underline a defect in the expansion process of the HC/HSCs in these AGMs, likely due to an increased apoptosis of these cells. In addition, we show that expression of Runx1, as well as expression of Meis1 and HoxB4, two target genes of Mpl known to play a role in self-renewal and expansion of HSCs (Sauvageau et al., 1994; Thorsteinsdottir et al., 1999; Antonchuk et al., 2001; Antonchuk et al., 2002; Hisa et al., 2004; Azcoitia et al., 2005), are down regulated in E10.5 Mpl-/- AGMs. Taken all together, our data indicate that $\mathrm{Mpl}$ is an active player during the first steps of definitive hematopoiesis establishment through direct regulation of the expression of transcription factors or genes important for self-renewal, proliferation and apoptosis of HSCs.

\section{Results}

\section{High hematopoietic content of E11.5 and} E10.5 Mpl-/- AGMs

In a previous study, we showed that E11.5 Mpl-/- AGMs presented an impaired HSC activity, and we postulated that lack of $\mathrm{Mpl}$ receptor led to a delayed production of clusters of definitive cells in the AGM region (Petit-Cocault et al., 2007). In order to further investigate this hypothesis, we first compared the hematopoietic content of E11.5 AGMs from Mpl-/- and C57Bl6 embryos. After dissection and dissociation by collagenase treatment, AGM cell suspensions were tested by FACS analysis for the presence of CD45 ${ }^{+} \mathrm{HCs}, \mathrm{CD}_{45}{ }^{+} \mathrm{c}-\mathrm{kit}^{\mathrm{hi}} \mathrm{HC} / \mathrm{HP}$ cells, and CD34 ${ }^{+} \mathrm{C}-\mathrm{kit}^{\text {hi }} \mathrm{HP} / \mathrm{HSC}$ enriched populations. No defect in the percentage of HC/HSCs was detected in Mpl-/- AGMs (sometimes a higher percentage was even detected in these later, as illustrated in Fig. 1A). When these percentages were related to the total number of cells per AGM, the number of CD $45^{+}$c-kithi and CD $34^{+}$c-kit ${ }^{\text {hi }}$ cells per AGM

\section{E11.5 AGM}

E10.5 AGM was equivalent in Mpl-/- and C57BI6 AGMs (Fig. 1C). Then the HP/HSC content of Mpl-/- AGMs at E11.5 does not corroborate the delayed production of these cells. Since the first clusters of $\mathrm{HC}$ emerge in the AGM region around E10.5, we next compared the CD $41^{+}$(early HCs), CD45+, CD $45^{+}$c-kithi, CD $144^{+} \mathrm{CD} 45^{+}$and CD34 ${ }^{+}$C-kithi content in AGMs from Mpl-/- and C57BI6 embryos at this stage. The total number of cells per AGM was found to be equivalent in Mpl-/- and C57BI6 (144 707 \pm 46733 versus 127863 \pm 23313 , respectively). As illustrated in Fig. 1B, the Mpl-/- AGMs did not show any defect in the percentage of $\mathrm{HCs}\left(\mathrm{CD} 41^{+}\right.$and

A
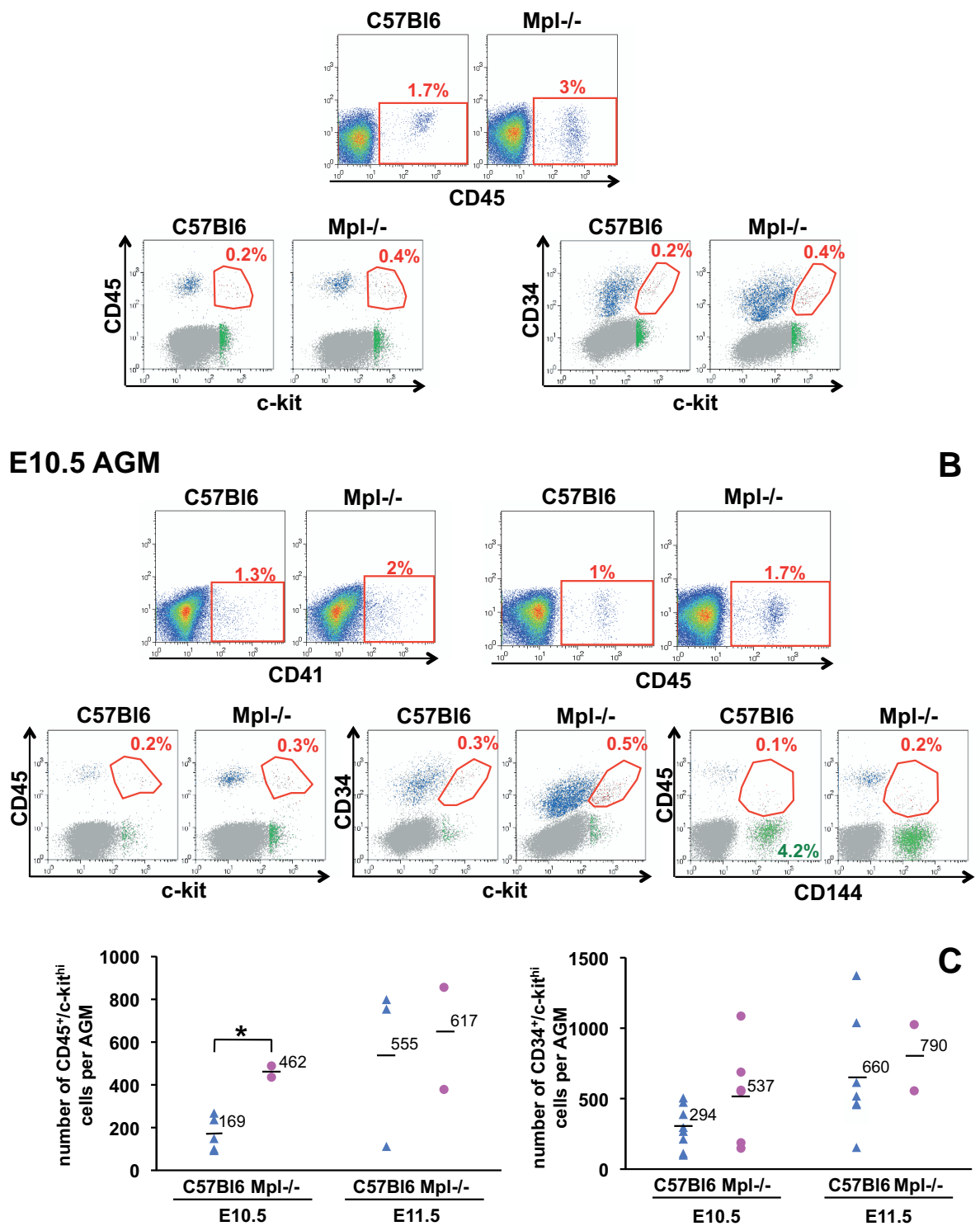

Fig. 1. Fluorescence-activated cell sorting (FACS) analysis of the hematopoietic content of Mpl-/- AGMs. AGMs dissected from E11.5 (A) and E10.5 (B) C57B/6 and Mpl-/-embryos were dissociated by collagenase treatment, and tested for the presence of $C D 45^{+}, C D 45^{+} \mathrm{C}-k i t^{\text {hi }}$ and

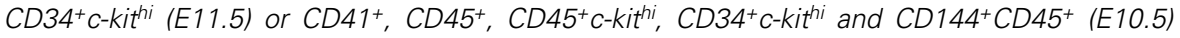
populations by FACS analysis. The majority of $c-k i t^{+}$cells express $c-k i t$ as a continuum. $C$-kithi refers to the distinct minor population, which expresses high levels of c-kit and is indicated by a polygon on the slot dots. (C) Comparison of the total number of $\mathrm{CD} 45^{+} \mathrm{c}-\mathrm{kithi}$ and $\mathrm{CD} 34^{+} \mathrm{c}-\mathrm{kithi}$ per C57BI6 and $\mathrm{Mpl}-\mathrm{-}-\mathrm{AGM}$. ${ }^{*} \mathrm{p}<0.05$. 
CD45+), HPs $\left(C D 45^{+} \mathrm{c}-\mathrm{kith}^{\mathrm{hi}}\right)$ or $\mathrm{HP} / \mathrm{HSCs}$ populations $\left(\mathrm{CD} 144^{+} \mathrm{CD} 45^{+}\right.$and $\left.\mathrm{CD} 34^{+} \mathrm{c}-\mathrm{kit}^{\mathrm{hi}}\right)$ : on the contrary, most of the time the percentages of hematopoietic cells were higher in the Mpl-/- AGMs. As for E11.5, when these percentages were related to the total number of cells per AGM, Mpl-/- AGMs presented an equivalent or greater number of hematopoietic cells than C57BI6 AGMs, as illustrated on Fig. $1 \mathrm{C}$ and $2 \mathrm{~A}$ for CD $34^{+} \mathrm{C}-\mathrm{kit}^{\mathrm{hi}}(537 \pm 316$ versus $294 \pm 143$ ) and CD45 ${ }^{+}$ckithi $^{\text {hi }} 462 \pm 26$ versus $169 \pm 71$ ) cells. The difference is statistically significant for the $\mathrm{CD} 45^{+} \mathrm{c}-\mathrm{kit}^{\mathrm{hi}}$ population $(p<0.05)$.

Taken all together, these data indicate that the LTR-HSCs defect that we described in the Mpl-/- E11.5 AGMs does not result from a delayed production of hematopoiesis at E10.5.

\section{E10.5 AGM explant cultures reveal a defect of $C D 34^{+}$c-kit ${ }^{\text {hi }}$ and $\mathrm{CD}_{45^{+}}$c-kit ${ }^{\text {hi }}$ expansion in Mpl-/- embryos}

Cultured E10/E11 AGMs have been shown to autonomously generate and expand HC/HSCs (Medvinsky and Dzierzak, 1996). We therefore compared the expansion of the CD45+c-kit ${ }^{\text {hi }}$ and CD $34^{+}$c-kithi populations after organ explant cultures of E10.5 Mpl-/- or C57BI6 AGMs. Both populations were amplified during Mpl-/- AGMs explant cultures, and after 3 days of culture an equivalent number of $C D 45^{+} c-k i t^{\text {hi }}$ and $C D 34^{+} c-k i t^{\text {hi }}$ cells per AGM was generated in Mpl-/- and C57BI6 AGMs (Fig. 2A and Fig. 2B, left panel). However, the amplification of these populations was less important for Mpl-/- AGMs than for C57BI6 AGMs. While an average of 13.2 fold increase of the $C D 45^{+} \mathrm{C}-\mathrm{kit}^{\mathrm{hi}}$ population was observed with C57BI6 AGMs explant cultures, Mpl-/- AGMs only displayed a 6.3 fold increase. This difference of expansion was further emphasized for the $\mathrm{CD} 34^{+} \mathrm{c}-\mathrm{kit}^{\mathrm{hi}}$ population, which was increased only 3 fold during the Mpl-/- explant culture and 7.6 fold during C57BI6 AGM culture $(p<0.05)$ (Fig. $2 A, B$, right panels). The most important defect in amplification was observed for the CD41+ population, which was not amplified at all in Mpl-/- AGMs (3800 CD41+ cells at D0, and 3350 at day 3 of culture explants), while a 2.7 fold amplification could be observed in C57BI6 AGMs (1900 CD41+ cells at D0, and 5190 at day 3 of culture explants).

\section{Increased apoptosis in E10.5 Mpl-/- AGM}

The reduced amplification of the $\mathrm{HC} / \mathrm{HSC}$ population during Mpl-/- AGM explant cultures prompted us to analyze the expression of proapoptotic $(\mathrm{Bim})$ and antiapoptotic $(\mathrm{BC} /-2$ and $B C /-X_{L}$ ) genes in $\mathrm{E} 10.5 \mathrm{Mpl}-/-$ and C57BI6 aortas. In fact, antiapoptotic and proapoptotic processes have been shown to be active in the earliest HSCs in the AGM region, suggesting that apoptosis was an important player in the regulation of these first HSCs expansion (Orelio et al., 2004). The level of Bim, BCl-2 and BC/$X_{L}$ expression was evaluated by q-PCR. A significant reduction of both $B c / 2$ (1.6 fold, $\mathrm{p}<0.001)$ and $B c /-X_{L}(1.5$ fold, $\mathrm{p}<0.05)$ antiapoptotic genes expression was observed in Mpl-/- AGMs, while the level of expression of the proapoptotic Bim gene was comparable in E10.5 Mpl-/- and C57BI6 AGMs (Fig. 3A).

The reduced expression of antiapoptotic genes in Mpl-/- AGM prompted us to examine whether the decreased expansion of CD $34^{+} \mathrm{c}-\mathrm{kithi}^{\mathrm{hi}}$ and $\mathrm{CD} 45^{+} \mathrm{c}-\mathrm{kit}^{\mathrm{hi}}$ populations in Mpl-/- AGMs after 3 days of explant culture could be related to an increased apoptosis. Flow cytometric analysis with Annexin V, an early marker of apoptosis and 7AAD staining was therefore performed on gated CD $45^{+}$c-kit ${ }^{\text {hi }}$ and CD $34^{+} c-k i t^{\text {hi }}$ fractions (Fig. 3 B,C). As shown on Fig. 3D, the percentage of Annexin $V^{+}$7AAD- preapoptotic cells in the CD $45^{+} \mathrm{C}-\mathrm{kit}^{\mathrm{hi}}$ and $\mathrm{CD} 34^{+} \mathrm{c}-\mathrm{kit}^{\mathrm{hi}}$ fractions of Mpl-/- AGM explants were increased 1.4 fold $(p<0.05)$ and 1.9 fold respectively, as compared to wild-type AGM explants. In addition, a 1.2 fold reduced expression of $B c l-2(p<0.05)$ and $B c l-X_{L}(p<0.05)$ was still detected in Mpl-/- AGM explants after 3 days of culture (Fig. 3E). This increased apoptosis can at least in part explain the reduced expansion of these populations during explant cultures of $\mathrm{Mpl}-/$ AGMs.

\section{Molecular targets of Mpl are downregulated during emer- gence of HP/HSCs in E10.5 Mpl-/- AGMs}

We attempted to determine the molecular mechanisms by which invalidation of $\mathrm{Mpl}$ receptor affects the temporal distribution and the expansion of HC/HSCs in the AGM. TPO has been shown to enhance HoxB4 and Meis1 expression (Kirito et al., 2003; Kirito et al., 2004; Orelio et al., 2004), two Hox genes known to play a role in self-renewal and expansion of adult HSCs. Expression of VEGF-A, a key factor in the process of induction of the hemangioblastic and hematopoietic development of ES cells (Choi et al., 1998) and required for HSC survival (Gerber et al.,

\begin{tabular}{ccc} 
A & \multicolumn{2}{c}{ CD45 $^{+}$c-kit $^{\text {hi }}$} \\
\cline { 2 - 3 } AGM E10.5 & D0 & D3 \\
\hline \multirow{2}{*}{ C57BI6 } & $169 \pm 71$ & $2686 \pm 1515$ \\
& {$[93-268]$} & {$[1183-4714]$} \\
\hline \multirow{2}{*}{ Mpl-/- } & $462 \pm 26$ & $1979 \pm 999$ \\
& {$[436-489]$} & {$[2760-3018]$} \\
\hline
\end{tabular}

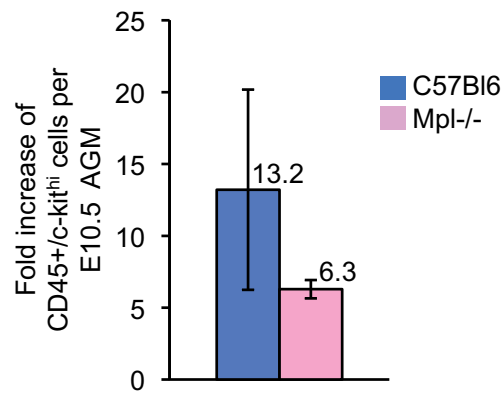

\begin{tabular}{ccc}
\multirow{2}{*}{ BGM E10.5 } & \multicolumn{2}{c}{ CD34+ $^{+}$c-kit } \\
\cline { 2 - 3 } & D0 & D3 \\
\hline \multirow{2}{*}{ C57BI6 } & $294 \pm 143$ & $2539 \pm 1249$ \\
& {$[99-505]$} & {$[715-4253]$} \\
\hline \multirow{2}{*}{ Mpl-/- } & $537 \pm 316$ & $1835 \pm 837$ \\
& {$[187-1086]$} & {$[390-2876]$} \\
\hline
\end{tabular}

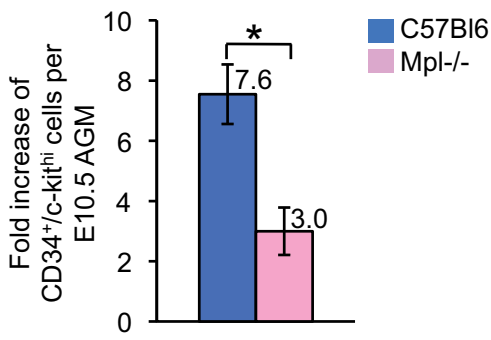

Fig. 2. Analysis of the hematopoietic content of Mpl-/- aorta-gonad-mesonephros (AGMs) before and after culture explant. Total number of $C D 45^{+} c-k i t^{h i}$ (A) and $C D 34^{+} c-k i t^{h i}$ (B) per C57BI6 or Mpl-/- AGMs $\pm S D(n=3)$ determined after FACS analysis at DO and D3 after culture explants are reported on the left tables. Range is indicated in the brackets [range]. Histograms on the right show the fold increase of $\mathrm{CD} 45^{+} \mathrm{c}-\mathrm{kithi}$ (A) and $\mathrm{CD} 34^{+} \mathrm{c}-\mathrm{kithi}$ (B) populations per E10.5 AGMs during the 3 days of culture explants. ${ }^{*} p<0.05$. 
2002), is also induced by TPO (Kirito et al., 2005). We therefore studied the level of transcription of these target genes by q-PCR in E10.5 AGMs from Mpl-/- and control embryos. As shown on Fig. 4A, both Meis1 and HoxB4 expression were found to be decreased in Mpl-/- AGM (1.5 fold, $\mathrm{p}<0.001$ and 1.2 fold respectively) compared to control C57BI6 AGMs, while no difference could be observed for VEGF-A expression.

The high hematopoietic content of E10.5 Mpl-/- AGMs is reminiscent of the change in the temporal distribution of HSCs observed with Runx1 haploinsufficiency (Cai et al., 2000). In addition, interactions between $\mathrm{Mpl}$ and Runx1 have been recently demonstrated: 3 Runx1 binding sites were found in the promoter region of $\mathrm{Mpl}$ (Heller et al., 2005), and Runx1 was described to work as a negative regulator of $\mathrm{Mpl}$ in adult HSC (Satoh et al., 2008). Furthermore, Hamelin et al. (Hamelin et al., 2006) have shown that TPO/Mpl signaling can regulate the activity of Runx1 through the ERK pathway. As a matter of fact, when we explored the level of Runx1 expression in Mpl-/- E10.5 AGMs by q-PCR, we found a 2.3 fold decrease compared to control E10.5 AGMs $(p<0.01)$ (Fig. 4B).

\section{Discussion}

In the present report, we investigated in more depth the HSCs defect that we described in E11.5 Mpl-/- AGMs, by performing an analysis of the hematopoietic content of these AGMs at the time of the first HSCs emergence (E10.5). We showed that at E10.5, $\mathrm{Mpl} / /-\mathrm{AGM}$ contains twice more HC/HSCs than C57BI6 AGM, as assessed by FACS analysis of the $\mathrm{CD} 41^{+}, \mathrm{CD} 45^{+}, \mathrm{CD} 45^{+} \mathrm{c}-\mathrm{kit}^{\mathrm{hi}}$, $\mathrm{CD} 34^{+} \mathrm{c}-\mathrm{kit}^{\mathrm{hi}}$, and CD $144^{+} \mathrm{CD} 45^{+}$populations. Interestingly enough, we found a two-fold reduction of Runx1 expression. This reduction of Runx1 expression is not observed anymore at E11.5, and seems therefore to be related to the developmental stage of emergence of $\mathrm{HC} / \mathrm{HSCs}$ in the aorta. Using a conditional deletion
A

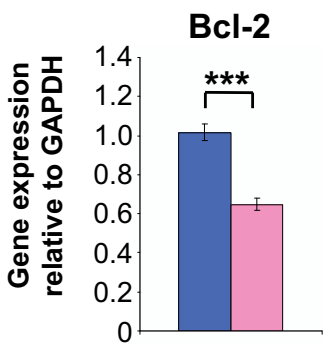

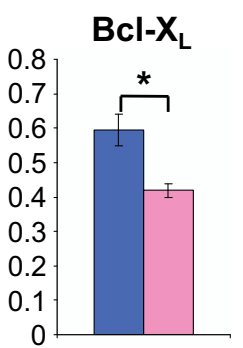

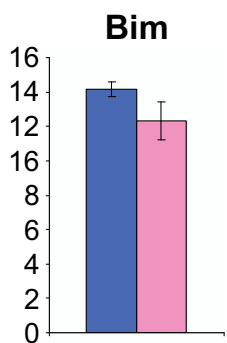

D

B
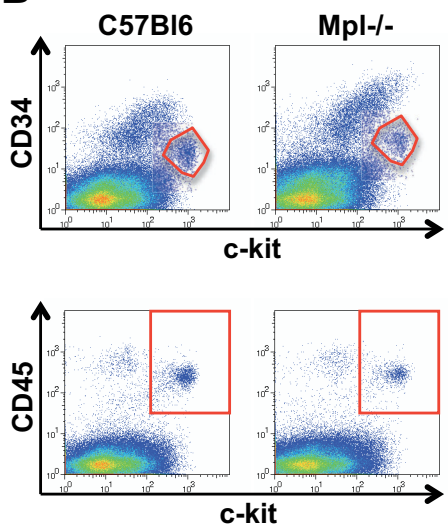

C
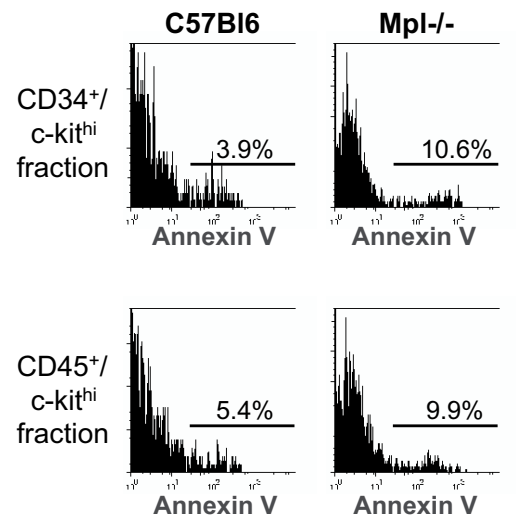

C57BI6

Mpl-/-

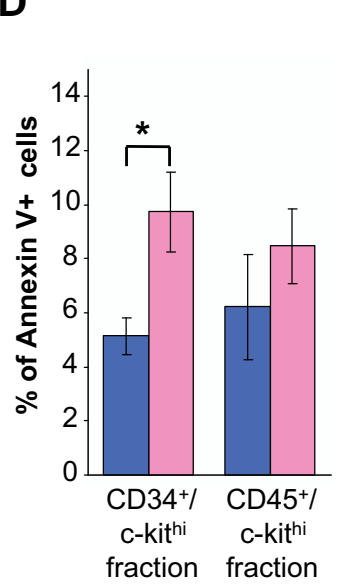

Fig. 3. Decreased expression of antiapoptotic genes in E10.5 Mpl-/- AGM and increased apoptosis in the CD45+c-kit ${ }^{\text {hi }}$ and CD34+c-kit ${ }^{\text {hi }}$ populations after explants culture. (A) Fresh E10.5 AGMs from Mpl-/- and C57B16 embryos were lysed with Trizol and total RNA was extracted. After reverse transcription, relative quantitative PCR ( $q-P C R$ ) was performed with gene-specific $P C R$ primers on a LightCycler 480 Instrument. Bcl2, BCl-XL, and Bim expression relative to GAPDH expression are reported on the histograms. (B,C,D) E10.5 AGM from Mpl--- and C57BI6 embryos were dissected and cultured as explants for 3 days. Single cells suspensions were prepared after collagenase treatment and stained with antibodies specific for CD45 or CD34 and c-kit and with Annexin Vand 7AAD. (B) FACS plots for $\mathrm{CD} 45^{+} \mathrm{c}-\mathrm{kit} \mathrm{t}^{\mathrm{hi}}$ and $\mathrm{CD} 34^{+} \mathrm{c}-\mathrm{kithi}$ populations for C57B/6 and Mpl-/AGMs. (C) Within the CD45+ $c-k i t^{\text {hi }}$ and $C D 34^{+} c-k i t^{\text {hi }}$ fractions of $A G M$, the percentage of Annexin $V^{+}$cells, which indicates the percentage of cells entering the apoptotic pathway, was determined. Representative histograms plots are shown. (D) The mean percentage of Annexin $\mathrm{V}^{+}$cells in the $C D 45^{+} \mathrm{C}^{-}$ $k i t^{h i}$ and $C D 34^{+} c-k i t^{h i}$ fractions of $A G M$ is represented on the histogram $(n=3)$. * $p<0.05$. (E) E10.5 AGM from $\mathrm{Mpl} / \mathrm{-}$ and C57Bl6 embryos were cultured as explants for 3 days, lysed with Trizol, and total RNA was extracted. After reverse transcription, relative quantitative $P C R$ ( $q-P C R$ ) was performed. $B C l-X L$, and Bim expression relative to GAPDH expression are reported on the histograms. ${ }^{*} p<0.05 ; * * *<0.005$. 
A

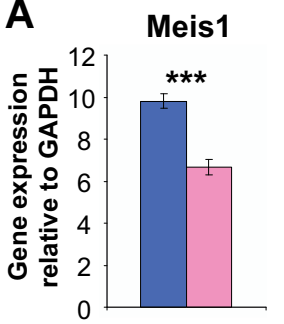

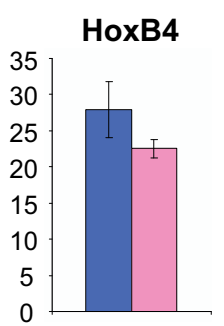

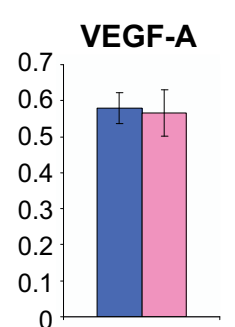

Fig. 4. Expression of $\mathrm{Mpl}$ target genes in E10.5 Mpl-/- aorta-gonad-mesonephros (AGM). Fresh E10.5 AGMs from Mpl--- and C57BI6 embryos were lysed with Trizol and total RNA was extracted. After reverse transcription, relative quantitative $P C R$ (q-PCR) was performed with gene-specific PCR primers on a LightCycler 480 Instrument. Meis1, HoxB4, VEGF-A (A) and Runx 1 (B) expression relative to GAPDH expression are reported on the histograms. Key: Blue C57BI6; Pink, Mpl-/. ** $p<0.01 ; * * * 0<0.005$.

of Runx1 in the VE-cadherin+ endothelial cells, Chen et al. recently demonstrated that Runx 1 expression is essential for the formation of HP cells and HSCs from the vasculature, but not thereafter (Chen et al., 2009). This, added to the fact that Runx1 has been shown to be regulated by ERK phosphorylation in response to TPO (Hamelin etal., 2006), let assume that during the transition from endothelial to hematopoietic cells in the aorta, Mpl receptor could play a role in the maintenance of Runx 1 activation not only via TPO-mediated ERK pathway, but also through direct regulation of Runx1 transcription.

When culture explants were set up to allow E10.5 AGMs expanding and generating HSCs in vitro while preserving the cellular microenvironment (Medvinsky and Dzierzak, 1996), a 2 to 2.5 fold defect of amplification of CD $45^{+} \mathrm{C}-\mathrm{kit}^{\mathrm{hi}} \mathrm{HP}$ and CD $34^{+} \mathrm{C}-\mathrm{kit}^{\mathrm{hi}}$ HSC populations was observed. Interestingly enough, expression of two homeogenes, HoxB4 and Meis1, was found to be reduced in E10.5 Mpl-/- AGMs. HoxB4 has been shown to be important for HSCs expansion (Antonchuk et al., 2002; Antonchuk et al., 2002; Schiedlmeier et al., 2003). A role of Meis 1 in the amplification and self-renewal of HSCs was demonstrated in the Meis $1 \mathrm{KO}$ mice, which present a defect of fetal liver HSCs (Hisa et al., 2004; Azcoitia et al., 2005). Both HoxB4 and Meis1 were described as Mpl target genes and shown to likely account for part of the favorable effects of TPO on adult HSC selfrenewal and expansion (Kaushansky, 2005). Their reduced level of expression in E10.5 Mpl-/- AGMs which present a defect of HP/HSC amplification in culture explant, let make the assumption that Mpl/ TPO signaling plays an important role also in HSCs self renewal and expansion during the establishment of definitive hematopoiesis.

Flow cytometric analysis with annexin $V$ and $7 A A D$

Fig. 5. Mpl, a key "sensor" gene of the AGM microenvironment? The genes affected in the Mpl-- environment during the different steps of emergence and production of the first HP/HSCs in the AGM between E10 and E11.5 are represented on the top part of the sketch. The consequent control of these different target genes by Mpl during these precise steps is shown on the bottom part of the sketch. FL, fetal liver; HE, hemogenic endothelium; SR, self-renewal.

B

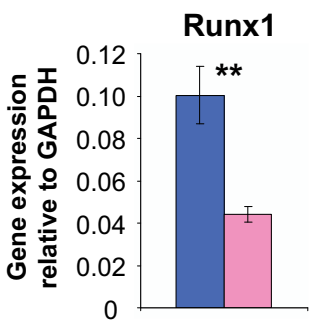

staining of $\mathrm{CD} 34^{+} \mathrm{C}-\mathrm{kit}^{\mathrm{hi}}$ and $\mathrm{CD} 45^{+} \mathrm{c}-\mathrm{kithi}^{\mathrm{hi}}$ populations after explants cultures revealed that the percentage of Annexin V+ 7AADpreapoptotic cells was higher in the Mpl-/explants as compared to C57BI6 explants. This increased apoptosis during culture explants can explain, at least in part, the defect of amplification of the CD34+c-kithi HSCs and CD $45^{+} c$-kithi HP cells, but also the impaired activity of E11.5 HSCs that we observed in Mpl-/- (Petit-Cocault et al., 2007). This is strengthened by the fact that expression of the antiapoptotic $B c /-2$ and $B C /-X_{L}$ genes (Pellegrini and Strasser, 1999; Adams and Cory, 2007), which have been shown to be important players in the regulation of apoptosis during the development of AGM HSCs (Orelio et al., 2004; Orelio and Dzierzak, 2007) is also significantly decreased in the E10.5 Mpl-/- AGM (1.6 fold and 1.5 fold for $B C /-2$ and $B C /-X$, respectively). A 1.2 fold decrease of both genes expression is still observed after 3 days of explants culture of these AGMs. Indeed, TPO has been demonstrated to act as a survival factor of adult HSCs (Kaushansky, 2005; Fox et al., 2002). It was shown to suppress growth factor withdrawal-induced apoptosis in the $\mathrm{MO} 7 \mathrm{e}$ cell line and to promote clonal growth with suppression of apoptosis of murine adult Sca1+lin cells (Borge et al., 1996; Ritchie et al., 1996). Cytokines are known to regulate the molecules involved in apoptosis, and therefore to influence adult hematopoietic cell survival (Sanz et al., 2000; Shinjyo et al., 2001; Karlsson et al., 2003). TPO was shown to support the survival of a TPO dependant leukemia cell line, UT7/Mpl, as well as normal megakaryocytic progenitors via the induction of $\mathrm{Bcl}-\mathrm{X}_{\mathrm{L}}$ (Kirito et al.,
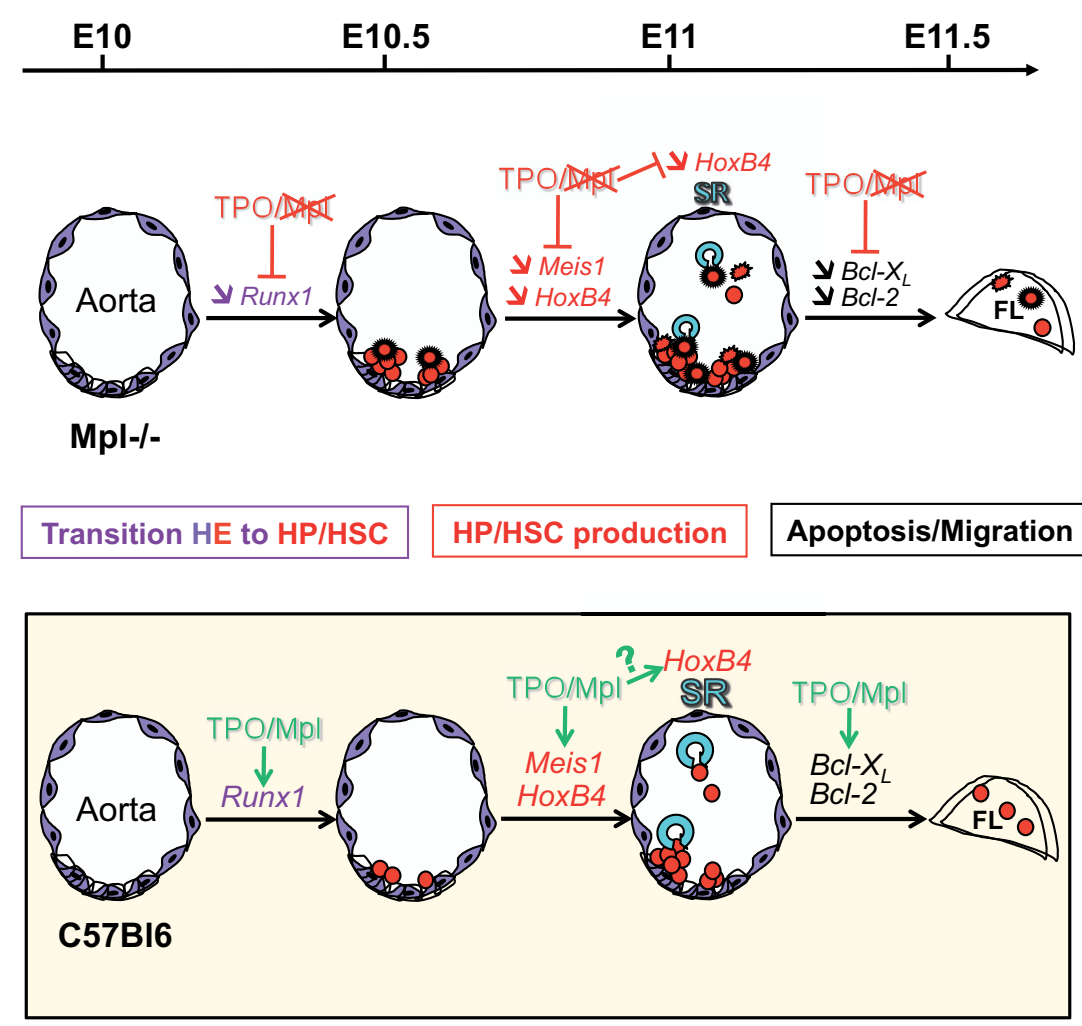
2002). More recently, IL-3 and IL-1 were shown to play also a role in the survival and regulation of HP cells and HSCs in the midgestation mouse AGM (Robin et al., 2006; Orelio et al., 2008). Our results indicate that TPO/Mpl signaling could also regulate apoptosis of the first HSCs emerging in E10.5 AGM, during the stage of transition from endothelial to hematopoietic cells, and during the phase of $\mathrm{HP} / \mathrm{HSC}$ production. Implication of $\mathrm{Bcl}-2$ in this process differs from the $\mathrm{Bcl}-2$ independent $\mathrm{HSC}$ survival and maintenance which has been described for adult HSCs (Qian et al., 2007)

Transcription factors have always been considered as master genes for the regulation of developmental hematopoiesis (Teitell and Mikkola, 2006). Our present results with Mpl indicate that a cytokine receptor can also be an active player in this process through direct regulation of the expression of transcription factors or genes important for self-renewal, proliferation and apoptosis of HSCs. Mp/ therefore looks like a key "sensor" gene of the AGM microenvironment, that can control different target genes depending on the precise steps of emergence of the first HSCs in the AGM region (Fig. 5).

\section{Material and Methods}

\section{Mice}

C57BI6 and $\mathrm{Mpl}-/-$ mice were bred and maintained in our animal facility. Heterozygous Mpl+/- mouse couples (B6-Ly5.2 background), kindly provided by Dr Fred de Sauvage (Genentech Inc.), have been interbred to generate homozygous $\mathrm{Mpl}-/-$ animals as previously described (Levin et al., 2001).

\section{Dissections and tissue/cell preparation}

Embryos were produced by natural mating of C57Bl6 or Mpl-/- mice. Vaginal plugs were checked in the morning, marking E0.5. Pregnant females were killed by cervical dislocation at different times of gestation. Uteri were taken and placed in phosphate-buffered saline (PBS) (Invitrogen). The stages of the embryos were confirmed by somite counting and morphological analysis.

\section{Explant cultures}

AGM were dissected and explanted AGMs were cultured onto Durapore $0.65 \mu \mathrm{m}$ filters (Millipore) at the air-liquid interface as described by Medinsky and Dzierzak (Medvinsky and Dzierzak, 1996). Briefly, tissues were cultured for 3 days at $37^{\circ} \mathrm{C}$ in $5 \% \mathrm{CO} 2$ in myeloid long-term culture media (IMDM supplemented with $12.5 \%$ FCS (Dominique Dutscher), $12.5 \%$ horse serum (Fisher), $0.5 \mathrm{mg} / \mathrm{l}$ ascorbic acid, $37 \mathrm{mg} / \mathrm{l}$ myo-inositol, $10 \mathrm{mg} / \mathrm{l}$ folic acid, $5 \times 10^{-5} \mathrm{M} \beta$-mercaptoethanol and $10^{-6} \mathrm{M}$ hydrocortisone hemisuccinate (Sigma) in the presence of $20 \mathrm{ng} / \mathrm{ml} \mathrm{TPO}$.

\section{FACS analysis}

Before staining, uncultured and cultured explants were treated for 30 minutes at $37^{\circ} \mathrm{C}$ with $0.125 \%$ type I collagenase (Sigma) in PBS with $10 \%$ FCS. Cells were dispersed by gentle pipetting, washed, filtrated through $70 \mu \mathrm{m}$ nylon mesh (Bio-technofix), resuspended in IMDM supplemented with $2 \%$ FCS and counted using Trypan Blue for exclusion of non viable cells. Cell staining was done in PBS with $0.5 \%$ bovine serum albumine (BSA) using the following antibodies: Allophycocyanin (APC)-CD45 (Biolegend), APC-CD34 (eBioscience), phycoerythrin (PE)-c-kit (Biolegend). CD144 antibody (BD Biosciences-Pharmingen) was biotinylated using FluoReporter Mini-Biotin kit (Molecular Probes). biotCD144 stained cells were detected by addition of PE-streptavidin (BD Biosciences-Pharmingen). For Annexin $V$ analysis, immuno-stained cells were resuspended in Annexin $\mathrm{V}$ buffer and stained with fluorescein isothiocyanate (FITC)-Annexin $\mathrm{V}$ (Biolegend) according to the manufacturer's guidelines. Dead cells were excluded by 7AAD (Beckman Coulter) staining, and FACS analysis was performed on a FACScalibur cytometer (BD Biosciences).

\section{RNA isolation, cDNA synthesis and q-PCR analysis}

Dissected AGM were lysed with Trizol (Invitrogen) and total RNA was extracted as recommended by the manufacturer. Reverse transcription was performed on $1 \mu \mathrm{g}$ of total RNA, as previously described (Challier et al., 2002). Relative quantitative PCR (q-PCR) was performed using the QuantiTect SYBR Green PCR Kit (Qiagen) according to the manufacturer's guidelines with gene-specific PCR primers on a LightCycler 480 Instrument (Roche). After one step at $95^{\circ} \mathrm{C}$ for 15 minutes to activate the HotStarTaq DNA polymerase (Qiagen), the samples were cycled 40 times (denaturation at $95^{\circ} \mathrm{C}$ for 20 seconds, annealing at $60^{\circ} \mathrm{C}$ for 30 seconds, and extension at $72^{\circ} \mathrm{C}$ for 20 seconds). Crossing point (Cp) values of the sequences of interest were measured using the LightCycler software (automated calculation by the second derivative maximum method). Relative expression was calculated according to the $E^{-D C p}$ formula. Data were normalized to Gapdh. The following primer sequences (5' to $\left.3^{\prime}\right)$ were used:

Bcl-2 forward primer (fw): TGTGGATGACTGAGTACCTGAACC

$\mathrm{Bcl}-2$ reverse primer (rv): AGAGACAGCCAGGAGAAATCAAAC

$\mathrm{Bcl}-\mathrm{X} \mathrm{fw}$ GGAAAGCGTAGACAAGGAGATG

Bcl-X rv GTTCCCGTAGAGATCCACAAAA

Bim $\mathrm{fw}$ ACGAGTTCAACGAAACTTACACAA

Bim rv CAATGCCTTCTCCATACCAGA

Meis $1 \mathrm{fw}$ ACAGCAGTGAGCAAGGTGATG

Meis1 rv CGCTTTTTGTGACGCTTTTTG

HoxB4 fw GGAGTTTCACTACAATCGCTACCT

HoxB4 rv TGGGCAACTTGTGGTCTTTT

VEGF-A fW CAGGCTGCTGTAACGATGAA

VEGF-A rv CTCCTATGTGCTGGCTTTGG

Runx1 fw CTACTCGGCAGAACTGAGAAATG

Runx1 rv ACGGTGATGGTCAGAGTGAAG

Gapdh fw ATGGTGAAGGTCGGTGTGAA

Gapdh rv AATGAAGGGGTCGTTGATGG

\section{Statistical analysis}

All experiments were analyzed using a 2-tailed Student $t$ test. Data were expressed as mean plus or minus standard error of the mean (SEM).

\section{Acknowledgements}

We thank the SEIVIL animal core facility for C57BI6 and Mpl--breeding and nursing. This work was supported by the Institut National de la Recherche Médicale (Inserm), and by grants from ARC/Inca and the Groupement des Entreprises Françaises dans la Lutte contre le Cancer (GEFLUC). MF was supported by the Ministère de l'Education Nationale de la Recherche et de la Technologie (MENRT), the Association ANRB Vaincre le Cancer and the French Society of Hematology (SFH).

\section{References}

ADAMS,J.M. and CORY,S. (2007). Bcl-2-regulated apoptosis: mechanism and therapeutic potential. Curr. Opin. Immunol. 19: 488-496.

ANTONCHUK,J., SAUVAGEAU,G., and HUMPHRIES,R.K. (2001). HOXB4 overexpression mediates very rapid stem cell regeneration and competitive hematopoietic repopulation. Exp. Hematol. 29: 1125-1134.

ANTONCHUK,J., SAUVAGEAU,G., and HUMPHRIES,R.K. (2002). HOXB4-induced expansion of adult hematopoietic stem cells ex vivo. Cell109: 39-45.

AZCOITIA,V., ARACIL,M., MARTINEZ,A., and TORRES,M. (2005). The homeodomain protein Meis1 is essential for definitive hematopoiesis and vascular patterning in the mouse embryo. Dev. Biol. 280: 307-320.

BOLLEROT,K., ROMERO,S., DUNON,D., and JAFFREDO,T. (2005). Core binding factor in the early avian embryo: cloning of Cbfbeta and combinatorial expression patterns with Runx1. Gene Expr. Patterns. 6: 29-39. 
BORGE,O.J., RAMSFJELL,V., VEIBY,O.P., MURPHY,M.J., JR., LOK,S., and JACOBSEN,S.E. (1996). Thrombopoietin, but not erythropoietin promotes viability and inhibits apoptosis of multipotent murine hematopoietic progenitor cells in vitro. Blood 88: 2859-2870.

CAI,Z., DE BRUIJN,M., MA,X., DORTLAND,B., LUTEIJN,T., DOWNING,R.J., and DZIERZAK,E. (2000). Haploinsufficiency of AML1 affects the temporal and spatial generation of hematopoietic stem cells in the mouse embryo. Immunity. 13: $423-431$.

CHALLIER,C., COCAULT,L., BERTHIER,R., BINART,N., DUSANTER-FOURT,I., UZAN,G., and SOUYRI,M. (2002). The cytoplasmic domain of Mpl receptor transduces exclusive signals in embryonic and fetal hematopoietic cells. Blood 100: 2063-2070.

CHEN,M.J., YOKOMIZO, T., ZEIGLER,B.M., DZIERZAK,E., and SPECK,N.A. (2009). Runx1 is required for the endothelial to haematopoietic cell transition but not thereafter. Nature 457: 887-891.

CHOI,K., KENNEDY,M., KAZAROV,A., PAPADIMITRIOU,J.C., and KELLER,G. (1998). A common precursor for hematopoietic and endothelial cells. Development 125: 725-732.

DE BRUIJN,M.F., SPECK,N.A., PEETERS,M.C., and DZIERZAK,E. (2000). Definitive hematopoietic stem cells first develop within the major arterial regions of the mouse embryo. EMBO J. 19: 2465-2474.

FOX,N., PRIESTLEY,G., PAPAYANNOPOULOU,T., and KAUSHANSKY,K. (2002). Thrombopoietin expands hematopoietic stem cells after transplantation. J. Clin. Invest 110: 389-394.

GERBER,H.P., MALIK,A.K., SOLAR,G.P., SHERMAN,D., LIANG,X.H., MENG,G., HONG,K., MARSTERS,J.C., and FERRARA,N. (2002). VEGF regulates haematopoietic stem cell survival by an internal autocrine loop mechanism. Nature 417: 954-958.

GODIN,I.E., GARCIA-PORRERO,J.A., COUTINHO,A., DIETERLEN-LIEVRE,F., and MARCOS,M.A. (1993). Para-aortic splanchnopleura from early mouse embryos contains B1a cell progenitors. Nature 364: 67-70.

HAMELIN,V., LETOURNEUX,C., ROMEO,P.H., PORTEU,F., and GAUDRY,M. (2006). Thrombopoietin regulates IEX-1 gene expression through ERK-induced AML1 phosphorylation. Blood 107: 3106-3113.

HELLER,P.G., GLEMBOTSKY,A.C., GANDHI,M.J., CUMMINGS,C.L., PIROLA,C.J., MARTA,R.F., KORNBLIHTT,L.I., DRACHMAN,J.G., and MOLINAS,F.C. (2005). Low Mpl receptor expression in a pedigree with familial platelet disorder with predisposition to acute myelogenous leukemia and a novel AML1 mutation. Blood 105: 4664-4670.

HISA,T., SPENCE,S.E., RACHEL,R.A., FUJITA,M., NAKAMURA,T., WARD,J.M., DEVOR-HENNEMAN,D.E., SAIKI,Y., KUTSUNA,H., TESSAROLLO,L., JENKINS,N.A., and COPELAND,N.G. (2004). Hematopoietic, angiogenic and eye defects in Meis1 mutant animals. EMBO J. 23: 450-459.

KARLSSON,R., ENGSTROM,M., JONSSON,M., KARLBERG,P., PRONK,C.J., RICHTER,J., and JONSSON,J.I. (2003). Phosphatidylinositol 3-kinase is essential for kit ligand-mediated survival, whereas interleukin-3 and flt3 ligand induce expression of antiapoptotic Bcl-2 family genes. J. Leukoc. Biol. 74: 923931.

KAUSHANSKY,K. (2005). Thrombopoietin and the hematopoietic stem cell. Ann. N. Y. Acad. Sci. 1044: 139-141.

KIRITO,K., FOX,N., and KAUSHANSKY,K. (2004). Thrombopoietin induces HOXA9 nuclear transport in immature hematopoietic cells: potential mechanism by which the hormone favorably affects hematopoietic stem cells. Mol. Cell Biol. 24: 6751-6762.

KIRITO,K., FOX,N., and KAUSHANSKY,K. (2003). Thrombopoietin stimulates Hoxb4 expression: an explanation for the favorable effects of TPO on hematopoietic stem cells. Blood102: 3172-3178.

KIRITO,K., FOX,N., KOMATSU,N., and KAUSHANSKY,K. (2005). Thrombopoietin enhances expression of vascular endothelial growth factor (VEGF) in primitive hematopoietic cells through induction of HIF-1\{alpha\}. Blood 105: 4258-4263.

KIRITO,K., WATANABE,T., SAWADA,K., ENDO,H., OZAWA,K., and KOMATSU,N. (2002). Thrombopoietin regulates $\mathrm{Bcl}-\mathrm{xL}$ gene expression through Stat5 and phosphatidylinositol 3-kinase activation pathways. J. Biol. Chem. 277: 83298337.

LEVIN,J., COCAULT,L., DEMERENS,C., CHALLIER,C., PAUCHARD,M., CAEN,J., and SOUYRI,M. (2001). Thrombocytopenic c-mpl(-/-) mice can produce a normal level of platelets after administration of 5-fluorouracil: the effect of age on the response. Blood98: 1019-1027.

MEDVINSKY,A. and DZIERZAK,E. (1996). Definitive hematopoiesis is autonomously initiated by the AGM region. Cel/86: 897-906.

MEDVINSKY,A.L., SAMOYLINA,N.L., MULLER,A.M., and DZIERZAK,E.A. (1993). An early pre-liver intraembryonic source of CFU-S in the developing mouse. Nature 364: 64-67.

NORTH,T., GU,T.L., STACY,T., WANG,Q., HOWARD,L., BINDER,M., MARINPADILLA,M., and SPECK,N.A. (1999). Cbfa2 is required for the formation of intra-aortic hematopoietic clusters. Development 126: 2563-2575.

NORTH,T.E., DE BRUIJN,M.F., STACY,T., TALEBIAN,L., LIND,E., ROBIN,C., BINDER,M., DZIERZAK,E., and SPECK,N.A. (2002). Runx1 expression marks long-term repopulating hematopoietic stem cells in the midgestation mouse embryo. Immunity. 16: 661-672.

ORELIO,C. and DZIERZAK,E. (2007). Bcl-2 expression and apoptosis in the regulation of hematopoietic stem cells. Leuk. Lymphoma 48: 16-24.

ORELIO,C., HAAK,E., PEETERS,M., and DZIERZAK,E. (2008). Interleukin-1mediated hematopoietic cell regulation in the aorta-gonad-mesonephros region of the mouse embryo. Blood112: 4895-4904.

ORELIO,C., HARVEY,K.N., MILES,C., OOSTENDORP,R.A., VAN DER,H.K., and DZIERZAK,E. (2004). The role of apoptosis in the development of AGM hematopoietic stem cells revealed by Bcl-2 overexpression. Blood103: 40844092.

PELLEGRINI,M. and STRASSER,A. (1999). A portrait of the Bcl-2 protein family: life, death, and the whole picture. J. Clin. Immunol. 19: 365-377.

PETIT-COCAULT,L., VOLLE-CHALLIER,C., FLEURY,M., PEAULT,B., and SOUYRI,M. (2007). Dual role of Mpl receptor during the establishment of definitive hematopoiesis. Development 134: 3031-3040.

QIAN,H., BUZA-VIDAS,N., HYLAND,C.D., JENSEN,C.T., ANTONCHUK,J., MANSSON,R., THOREN,L.A., EKBLOM,M., ALEXANDER,W.S., and JACOBSEN,S.E. (2007). Critical role of thrombopoietin in maintaining adult quiescent hematopoietic stem cells. Cel/ Stem Cel/1: 671-684.

RITCHIE,A., VADHAN-RAJ,S., and BROXMEYER,H.E. (1996). Thrombopoietin suppresses apoptosis and behaves as a survival factor for the human growth factor-dependent cell line, M07e. Stem Cells 14: 330-336.

ROBIN,C., OTTERSBACH,K., DURAND,C., PEETERS,M., VANES,L., TYBULEWICZ,V., and DZIERZAK,E. (2006). An unexpected role for IL-3 in the embryonic development of hematopoietic stem cells. Dev. Cel/11: 171-180.

SANZ,C., BENITO,A., INOHARA,N., EKHTERAE,D., NUNEZ,G., and FERNANDEZLUNA,J.L. (2000). Specific and rapid induction of the proapoptotic protein Hrk after growth factor withdrawal in hematopoietic progenitor cells. Blood95: 2742 2747.

SATOH,Y., MATSUMURA,I., TANAKA,H., EZOE,S., FUKUSHIMA,K., TOKUNAGA,M., YASUMI,M., SHIBAYAMA,H., MIZUKI,M., ERA,T., OKUDA,T., and KANAKURA,Y. (2008). AML1/RUNX1 works as a negative regulator of CMpl in hematopoietic stem cells. J. Biol. Chem. 283: 30045-30056.

SAUVAGEAU,G., LANSDORP,P.M., EAVES,C.J., HOGGE,D.E., DRAGOWSKA,W.H., REID,D.S., LARGMAN,C., LAWRENCE,H.J., and HUMPHRIES,R.K. (1994). Differential expression of homeobox genes in functionally distinct CD34+ subpopulations of human bone marrow cells. Proc. Natl. Acad. Sci. USA 91: 12223-12227.

SCHIEDLMEIER,B., KLUMP,H., WILL,E., RMAN-KALCEK,G., LI,Z., WANG,Z., RIMEK,A., FRIEL,J., BAUM,C., and OSTERTAG,W. (2003). High-level ectopic HOXB4 expression confers a profound in vivo competitive growth advantage on human cord blood CD34+ cells, but impairs lymphomyeloid differentiation. Blood 101: 1759-1768.

SHINJYO,T., KURIBARA,R., INUKAI,T., HOSOI,H., KINOSHITA,T., MIYAJIMA,A., HOUGHTON,P.J., LOOK,A.T., OZAWA,K., and INABA,T. (2001). Downregulation of Bim, a proapoptotic relative of $\mathrm{Bcl}-2$, is a pivotal step in cytokine-initiated survival signaling in murine hematopoietic progenitors. Mol. Cel/ Biol. 21: 854 864.

TEITELL,M.A. and MIKKOLA,H.K. (2006). Transcriptional activators, repressors, and epigenetic modifiers controlling hematopoietic stem cell development. Pediatr. Res. 59: 33R-39R.

THORSTEINSDOTTIR,U., SAUVAGEAU,G., and HUMPHRIES,R.K. (1999). Enhanced in vivo regenerative potential of HOXB4-transduced hematopoietic 
stem cells with regulation of their pool size. Blood94: 2605-2612.

YOKOMIZO,T., OGAWA,M., OSATO,M., KANNO,T., YOSHIDA,H., FUJIMOTO,T., FRASER,S., NISHIKAWA,S., OKADA,H., SATAKE,M., NODA,T.,
NISHIKAWA,S., and ITO,Y. (2001). Requirement of Runx1/AML1/PEBP2alphaB for the generation of haematopoietic cells from endothelial cells. Genes Cel/s6: 13-23.

\section{Further Related Reading, published previously in the Int. J. Dev. Biol.}

See our recent Special Issue Placenta edited by Joan S. Hunt and Kent L. Thornburg at: http://www.ijdb.ehu.es/web/contents.php?vol=54\&issue=2-3

Tracing the hemangioblast during embryogenesis: developmental relationships between endothelial and hematopoietic cells Thierry Jaffredo, Karine Bollerot, Daisuke Sugiyama, Rodolphe Gautier and Cécile Drevon Int. J. Dev. Biol. (2005) 49: 269-277

Of birds and mice: hematopoietic stem cell development

Isabelle Godin and Ana Cumano

Int. J. Dev. Biol. (2005) 49: 251-257

Embryonic development of the human hematopoietic system

Manuela Tavian and Bruno Péault

Int. J. Dev. Biol. (2005) 49: 243-250

Multilineage hematopoietic progenitor activity generated autonomously in the mouse yolk sac: analysis using angiogenesisdefective embryos

Christine Rampon and Philippe Huber

Int. J. Dev. Biol. (2003) 47: 273-280

Pathways in blood and vessel development revealed through zebrafish genetics

Philip S Crosier, Maggie L Kalev-Zylinska, Christopher J Hall, Maria Vega C Flores, Julia A Horsfield and Kathryn E Crosier Int. J. Dev. Biol. (2002) 46: 493-502

Embryonic stem cells and transgenic mice in the study of hematopoiesis

S H Orkin

Int. J. Dev. Biol. (1998) 42: 927-934
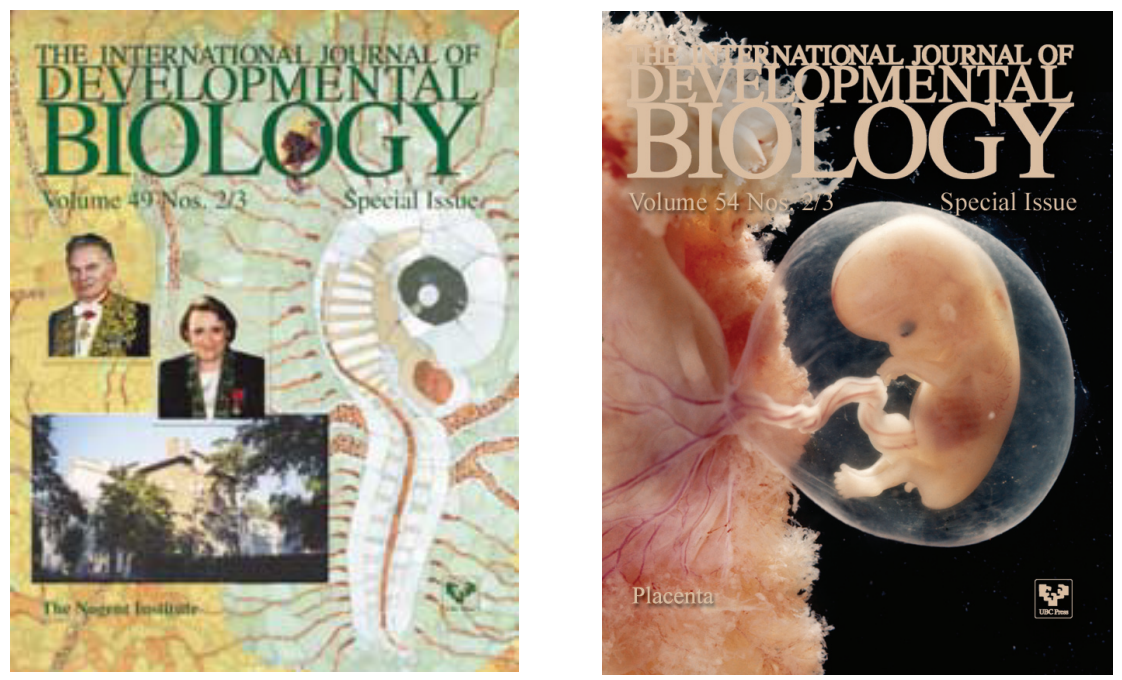

5 yr ISI Impact Factor $(2009)=3.253$

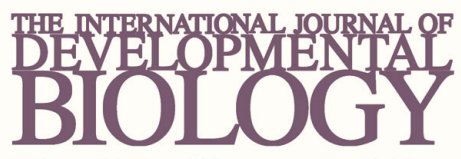

Volume 54 Nos. $6 / 7$

Special Issue

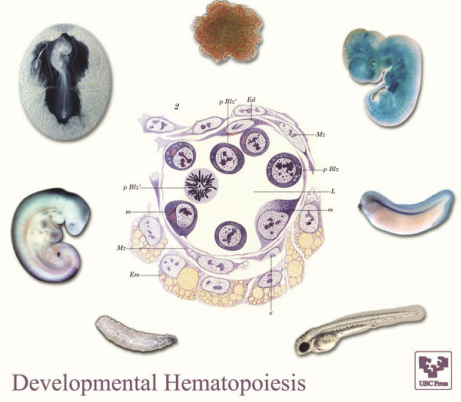

Developmental Hematopoiesis 